\title{
Designing an IoT Agriculture Monitoring System for Improving Farmer's Acceptance of Using IoT Technology
}

\author{
Siti Aisyah Binti Anas \\ Faculty of Electronics and Computer Engineering \\ Universiti Teknikal Malaysia Melaka \\ Malacca, Malaysia \\ aisyah@utem.edu.my
}

\author{
Ranjit Singh Sarban Singh \\ Faculty of Electronics and Computer Engineering \\ Universiti Teknikal Malaysia Melaka \\ Malacca, Malaysia \\ ranjit.singh@utem.edu.my
}

\author{
Nur Adilah Binti Kamarudin \\ Electrical Electronic Validation, Engineering Validation, R\&D Engineering \\ Perusahaan Otomobil Nasional Sdn Bhd \\ Shah Alam, Selangor, Malaysia \\ NurAdilah@proton.com
}

\begin{abstract}
This paper describes Agri-Snaps, an Internet of Things (IoT) agriculture monitoring system designed to improve farmers' acceptance of using IoT technology in their farm field. Agri-Snaps consists of four dedicated sensor circuit modules that integrate magnetic pogo pin connectors for easier assembly with the controller circuit module. This work investigated how such a design can enable the farmers to understand how 1) to assemble, 2) self-troubleshoot, and 3) maintain the monitoring system independently without requiring expertise on the farm site. Userexperience testing was conducted with ten participants to validate Agri-Snaps's viability. The results showed that those participants positively rated Agri-Snaps as attractive, easy to understand and assemble, exciting, and innovative compared to the typical agriculture monitoring systems.
\end{abstract}

Keywords-Internet of Things; agriculture; industrial design; sensors; embedded system; human-computer interaction

\section{INTRODUCTION}

Internet of Things (IoT) is driving change in agriculture. It enables sensors on a farm to remotely monitor and give realtime data to the farmer, such as detecting the current environmental conditions [1]. The implementation of IoT also allows the farmers to increase farm production effectively throughout the year. In line with the Fourth Industrial Revolution (IR 4.0), farmers are always encouraged to implement smart farming using IoT technology for better decision making [2, 3]. Unfortunately, most farmers are still hesitant to adopt IoT on their farm sites and prefer traditional farming practices, resulting in lower crop yields [4]. A deeper investigation revealed 4 main reasons why farmers were not ready to implement IoT in their farm fields [2,5]: 1) the level of education required to become familiar with the technology, 2 ) the lack of engineering skills needed to install the system, 3) the troubleshooting process required to sustain the system, and 4) the high cost of implementing the system. While previous studies focus on the benefits of implementing IoT in the agriculture sector, to the best of our knowledge, there are no studies on improving the farmers' acceptance of using IoT technology. Hence, this work focuses on how a typical IoT agricultural monitoring system can be enhanced to enable the farmers to implement the system without requiring particular skills. With an improved design, farmers can easily understand how to self-integrate, self-troubleshoot and self-maintain the IoT environmental monitoring system without requiring expertise on the farm site. As a result, it can increase the farmers' willingness to accept innovative IoT technology and help them gain control over growing crops. In the end, such technology will allow them to run a more predictable, efficient, and profitable agribusiness [4].

\section{BACKGROUND}

In previously conducted research, authors in $[6,7]$ developed an automatic IoT environmental control system to optimize mushroom production. The developed system enables the farmer to remotely monitor and analyze the environmental conditions of the mushroom production house. Based on the analyzed data, the system will automatically control the irrigation system to ensure the temperature level is optimum. This smart mushroom system has proven to optimize the mushroom's quality and productivity. Authors in [8] developed an automatic web-based IoT agriculture fertigation system that allows the farmers to remotely set the fertigation schedule. The system also enables the farmers to formulate the fertilizer composition. In this way, the farmers can virtually manage their automated fertigation system by accessing the website using their mobile devices. Authors in [9] proposed an IoT 
smart farming framework of cotton crops that supports smart reasoning based on the data streams from the embedded sensors deployed inside the cotton field. As a result, the framework provided real-time results that helped farmers make efficient event detection decisions. In addition, authors in [1012] developed an automatic IoT irrigation system that measured and maintained the moisture content in the soil. Through the system, the farmers can optimize the usage of water fertilizers while maximizing the yield of the crops. To summarize, all the mentioned IoT research related to agriculture enables the farmers to increase the crop yield compared to conventional methods. This nonetheless proved that IoT technologies help to improve agricultural and farming industries. While previous research focused on the benefits of implementing IoT technology, there are no studies on the willingness of the farmer to accept, adopt and sustain the IoT system. Therefore, this work focuses on designing and developing a simple and intuitive IoT agriculture monitoring system that allows the farmers to understand how to implement it without much effort. Such a design could improve the farmers' acceptance of IoT technology in their farm fields.

\section{DESIGN AND IMPLEMENTATION}

A typical IoT agricultural monitoring system is generally built with a complex architecture and is difficult for farmers to comprehend [13]. Therefore, the complex architectural design of the IoT agricultural monitoring system needs to be separated into two modules: 1) the controller module and 2) the sensor modules. The following sections will describe how the two modules are designed and developed to improve farmers' acceptance of implementing IoT technology in the farm field.

\section{A. 3D Enclosure Design}

One key design decision was to allow the farmers to clearly understand how to assemble and easily set up the IoT weather monitoring system independently. Figure 1 shows 3D enclosures uniquely designed to house the controller and the sensor modules. The controller enclosure is designed to fit the system's brain (ESP8266 Wi-Fi module). Four sensor enclosures were designed to fit: the humidity sensor (ESP01), the rain index sensor, the light intensity sensor, and the temperature sensor (DS18B20). Color-coded schemes [14] and emboss sensor icons [15] were also integrated into the designed enclosure for easy differentiation and understanding. For example, the blue enclosure with the water drop emboss icon represents the humidity sensor. Slot joints were also added to create a joint between two modules. Therefore, by referring to the matched emboss icon, such a design allows the user to easily assemble the system by inserting the sensor module into the controller module slot joint, respectively. Screw-fastened covers were also integrated to protect the electronic circuits placed inside the enclosure. Figure 2 shows the microcontroller and the circuit sensor modules placed inside the $3 \mathrm{D}$ printed enclosures to ensure the electronic components are protected in any environment. However, putting the sensors inside the enclosures can result in an inaccurate sensor reading that might directly lead to substantial risks [16]. Therefore, each of the sensors used for this system is mounted outside of the enclosure to provide a better and more accurate sensor reading.

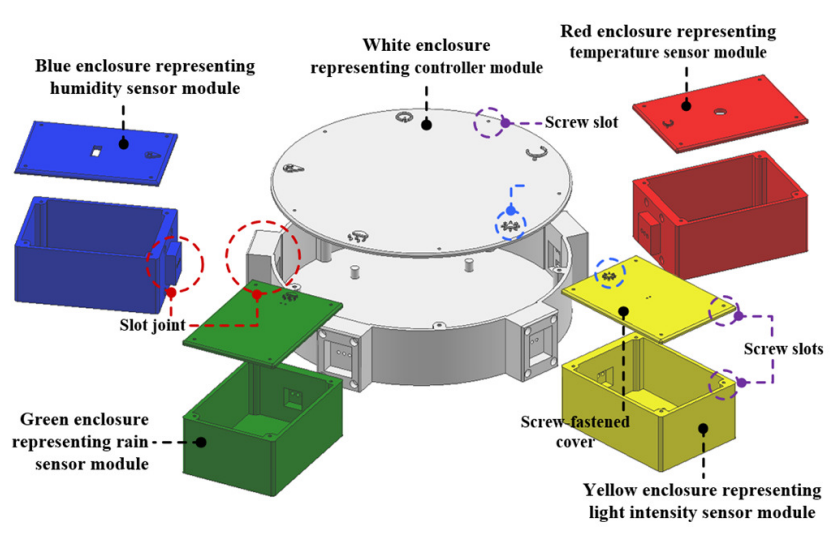

Fig. 1. 3D casing design of Agri-Snaps.
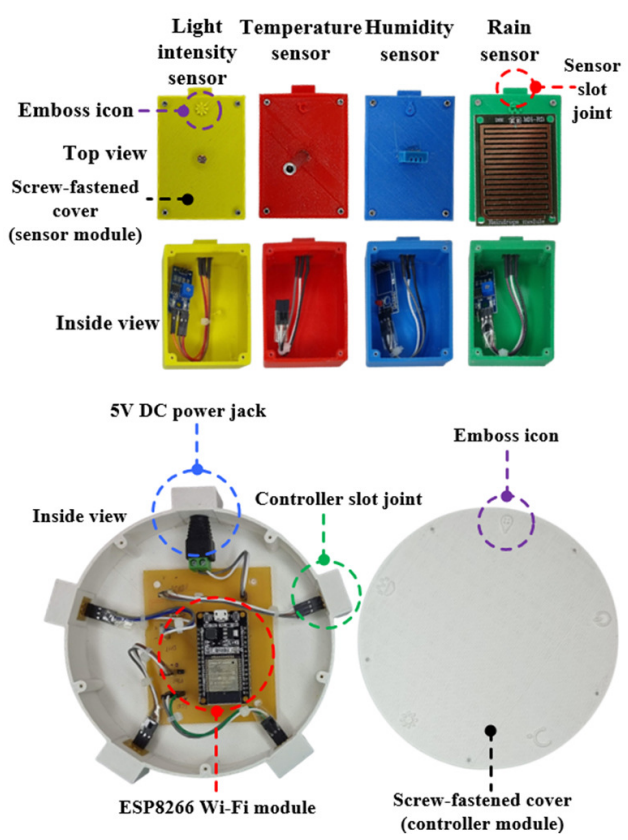

Fig. 2. Agri-Snaps's 3D printed enclosures.

\section{B. Pogo Pins and Magnets}

The electronic connection of Agri-Snaps was inspired by the work of Bdeir on littleBits [17]. Like littleBits, pogo pins were used, specifically at the slot joint, to allow the current/signal to flow from the controller module to the sensor module and vice versa (Figure 3). Strong magnets were also used to enable a solid connection between the controller and the sensor modules. Therefore the current/signal can flow smoothly throughout the system. Figure 3 shows the placement of the pogo pins and magnets that are embedded into the designed enclosure. Each sensor module enclosure is integrated with different magnetic poles combinations as a safety precaution. Such combinations will protect the system if the user accidentally inserts the sensor module at the wrong slot joint, damaging the system's circuit. For example, as shown in Figure 5, magnets will repel each other when inserting a light intensity sensor module at the temperature slot joint. 


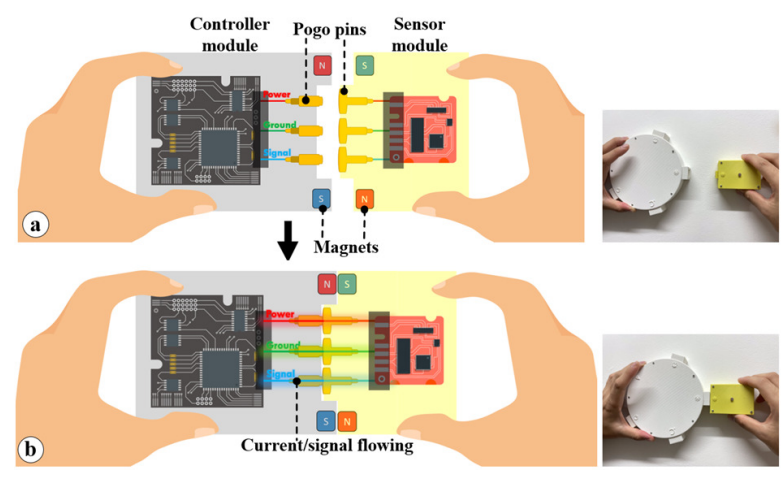

Fig. 3. Pogo pins and magnets as an enabler mechanism to allow current/signal to flow from the controller to the sensor module and vice versa.

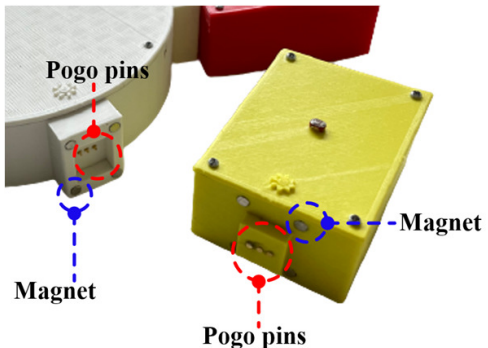

Fig. 4. Integration of pogo pins and magnets into the $3 \mathrm{D}$ printed enclosures.

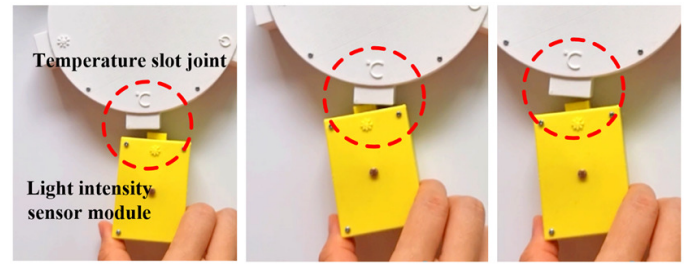

Fig. 5. Magnets will push the sensor module away if the user tries to insert the sensor module at the wrong slot joint.

\section{Power Supply}

A typical 5V DC power connector is used to power the Agri-Snaps. It operates at $3.3 \mathrm{~V}$ and has a maximum current draw of $70 \mathrm{~mA}$ with a power consumption of $231 \mathrm{~mW}$. Generally, Agri-Snaps will consume $2.024 \mathrm{kWh}$ over the year, and the electricity bill will only cost around 7 USD per year. Therefore, implementing Agri-Snaps will not going to break the user's bank.

\section{Assembling Procedures}

Agri-Snaps can be easily assembled. First, the user needs to match the emboss icon on top of the enclosures (Figure 6(a)). Then, the magnets will snap the sensor module into the controller module's joint slot (Figure 6(b-e)). Any 5V DC power supply can be used to turn on Agri-Snaps. As shown in Figure 6(f), a USB power supply cable connected to a waterproof solar power bank and plugged into the power slot is used to power up Agri-Snaps. Afterwards, the user can decide where to integrate the system appropriately, as shown in Figure 7.
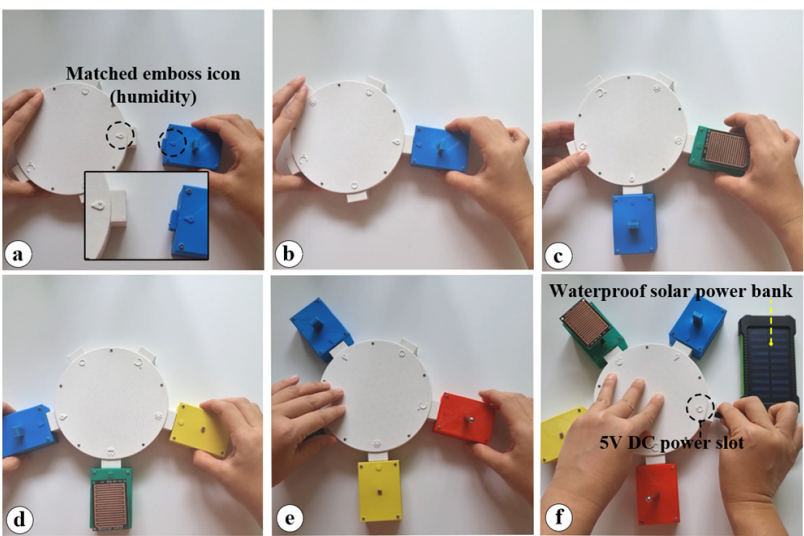

Fig. 6. Assembling procedure of the Agri-Snaps.

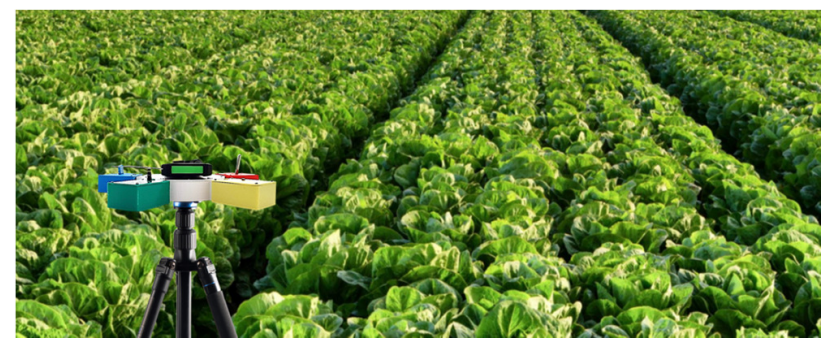

Fig. 7. Agri-Snaps placed directly in the farm field.

\section{E. IoT Data Visualizations}

ThingSpeak is a web-based open API IoT source information platform that can store sensor data and graphically present it on the web. Agri-Snaps uses the ESP8266 NodeMCU microcontroller to send the humidity, rain index, light intensity, and temperature data to the ThingSpeak platform over the Internet. As shown in Figure 8, ThingSpeak allows the farmers to visualize a live data stream from any web browser or mobile device and help them make accurate and proactive decisions.

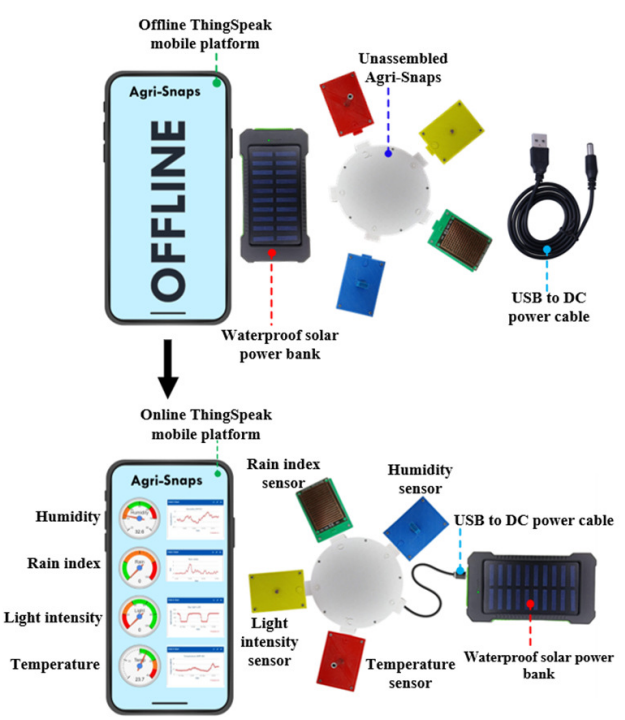

Fig. 8. Data visualization on ThingSpeak. 
Another key design was allowing the farmers to easily troubleshoot the system when required. Suppose two of the sensor modules are not functioning properly due to broken, ageing or similar reasons (Figure 9). In that case, Agri-Snaps will alert the user through the ThingSpeak platform. Therefore, the user simply needs to snap out the broken sensor modules and buy new modules from the supplier. Apart from that, AgriSnaps can be customized following the user's requirements. For example, the system will understand and function accordingly if the user decides to use humidity and temperature sensors in a certain situation, as shown in Figure 10.

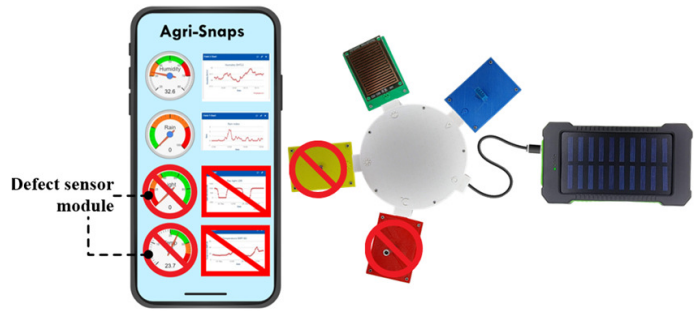

Fig. 9. Notification of defect sensor modules.

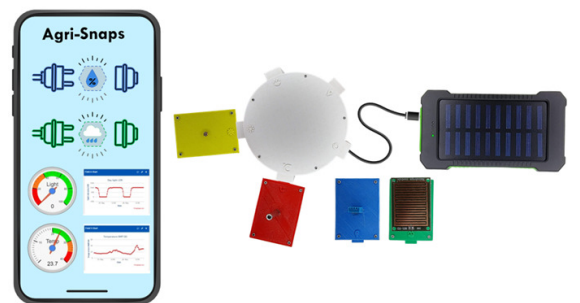

Fig. 10. Notification of unconnected sensor modules.

\section{USER-EXPERIENCE TESTING}

Before testing, a typical IoT agriculture monitoring system (Figure 11) was developed to allow the users to use both the typical system and the Agri-Snaps. The user-experience testings for both system designs were compared and analyzed at the end of the testing.

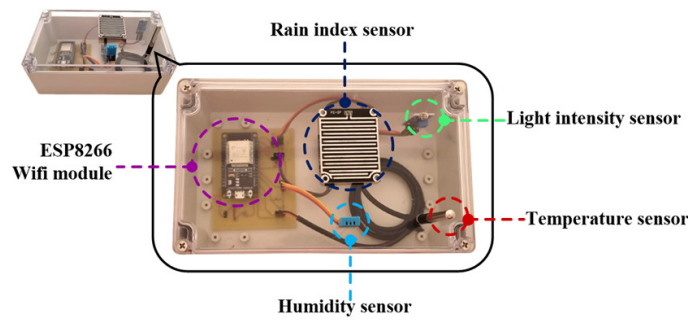

Fig. 11. A typical IoT agriculture monitoring system.

\section{A. Participants}

Within-subjects testing was designed to involve 10 farmers ( 7 males, 3 females, age range: 25 to 45 ). The farmers were evenly separated into two groups of 5 participants, groups A and $\mathrm{B}$.

\section{B. Procedures}

Each participant was required to experience using the typical system for group A for 7 days. After that, they were asked to fill out a set of questionnaires. Then, the procedure was repeated again by letting the participants in group A experience Agri-Snaps. After 7 days, they filled out the same set of questionnaires again. The same procedures were implemented for group B, except they were experiencing using Agri-Snaps initially and then the typical system. These procedures were designed to eliminate the ordering effects that might affect the testing's outcome [18].

\section{Measurement}

The User Experience Questionnaire (UEQ) [19] was used to measure the subjective impression of users towards a product (Figure 12). The UEQ questionnaire consistsed of 26 items divided into 6 individual scales: 1) Attractiveness indicated the overall impression of the product, 2) Perspicuity which measured the difficulty of participants to get familiar and learned how to use the product, 3) Efficiency was the ability of participants to realize how to use the product without unnecessary effort, 4) Dependability refers to the predictability when using the product, 5) Stimulation shows participants' excitement and motivation to use the product, and 6) Novelty indicated whether the product was innovative, creative, and able to catch the participant's interest. Items 1, 12, 14, 16, 24, 25 were related to the Attractiveness scale, items 2, 4, 13, 21 were related to the Perspicuity scale, items 9, 22, 23 were related to the Efficiency scale, items 8, 11, 17, 19 were related to the Dependability scale, items $5,6,7,18$ were related to the Stimulation scale, and items $3,10,15,26$ were related to the Novelty scale. Participants must express their experience with both the typical system and Agri-Snaps by marking each item of the UEQ questionnaire with a 6-point Likert scale.

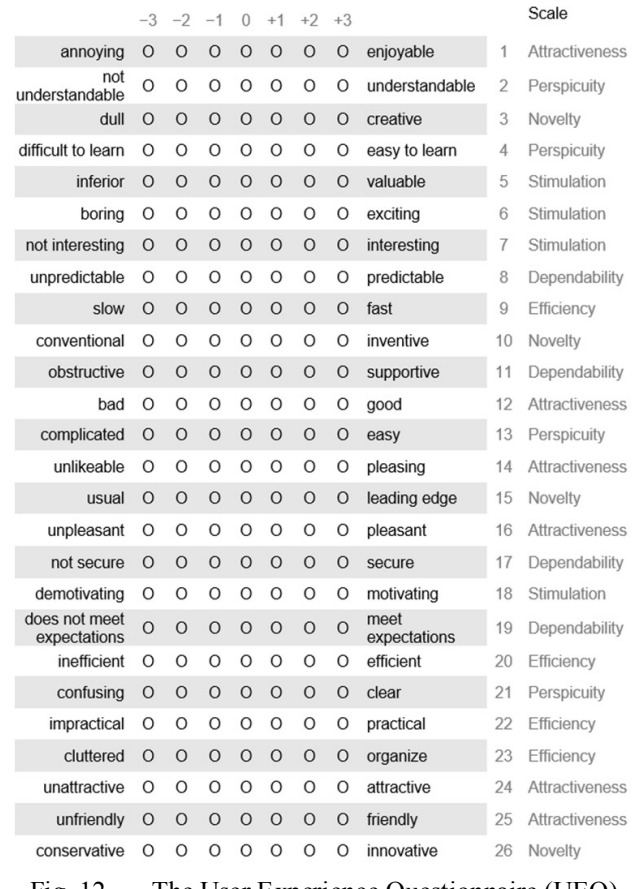

Fig. 12. The User Experience Questionnaire (UEQ). 


\section{Results and Discussion}

All the measured items have been summarized according to the scale as tabulated in Table I. The unshaded rows were the percentage of the participants' rating towards Agri-Snaps. The shaded rows were the percentage of the participants' rating towards the typical circuit. To better understand the participants' responses, Figure 13 shows the overall mean values of the UEQ questionnaire for each scale. The UEQ scale mean ranges from -3 (horrible bad) to +3 (extremely good), with values between -0.8 and 0.8 indicating a neutral assessment [19].

TABLE I. PERCENTAGE OF PARTICIPANTS THAT RATED EACH OF THE ITEMS ACCORDING TO THE SCALE

\begin{tabular}{|c|c|c|c|c|c|c|c|c|}
\hline Scales & Items & -3 & -2 & -1 & 0 & 1 & 2 & 3 \\
\hline \multirow{12}{*}{ 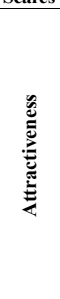 } & \multirow{2}{*}{$\begin{array}{l}\text { Annoying/ } \\
\text { Enjoyable }\end{array}$} & . & 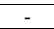 & 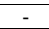 & 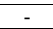 & - & $50 \%$ & $50 \%$ \\
\hline & & $20 \%$ & $10 \%$ & $40 \%$ & $10 \%$ & $20 \%$ & - & - \\
\hline & \multirow{2}{*}{$\begin{array}{c}\text { Bad/ } \\
\text { Good }\end{array}$} & - & - & - & - & - & $40 \%$ & $60 \%$ \\
\hline & & $20 \%$ & $30 \%$ & $20 \%$ & $30 \%$ & - & - & - \\
\hline & \multirow{2}{*}{$\begin{array}{c}\text { Unlikeable/ } \\
\text { Pleasing }\end{array}$} & - & - & - & - & $10 \%$ & $90 \%$ & - \\
\hline & & $20 \%$ & $40 \%$ & $20 \%$ & $10 \%$ & $10 \%$ & - & - \\
\hline & \multirow{2}{*}{$\begin{array}{c}\text { Unpleasant/ } \\
\text { Pleasant }\end{array}$} & - & - & - & - & $20 \%$ & $80 \%$ & - \\
\hline & & $10 \%$ & $10 \%$ & $30 \%$ & $50 \%$ & - & - & - \\
\hline & \multirow{2}{*}{$\begin{array}{l}\text { Unattractive/ } \\
\text { Attractive }\end{array}$} & - & - & - & - & $20 \%$ & $40 \%$ & $40 \%$ \\
\hline & & $30 \%$ & $10 \%$ & $30 \%$ & $30 \%$ & - & - & - \\
\hline & \multirow{2}{*}{$\begin{array}{l}\text { Unfriendly/ } \\
\text { Friendly }\end{array}$} & - & - & - & - & - & $40 \%$ & $60 \%$ \\
\hline & & $10 \%$ & $30 \%$ & $40 \%$ & $20 \%$ & - & - & - \\
\hline \multirow{8}{*}{ 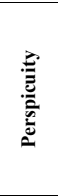 } & \multirow{2}{*}{$\begin{array}{l}\text { Not understandable/ } \\
\text { Understandable }\end{array}$} & - & - & - & - & $20 \%$ & $60 \%$ & $20 \%$ \\
\hline & & $30 \%$ & $10 \%$ & $20 \%$ & $10 \%$ & $30 \%$ & - & - \\
\hline & \multirow{2}{*}{$\begin{array}{l}\text { Difficult to learn/ } \\
\text { Easy to learn }\end{array}$} & - & - & - & - & - & $50 \%$ & $50 \%$ \\
\hline & & $30 \%$ & - & $40 \%$ & $30 \%$ & - & - & - \\
\hline & \multirow{2}{*}{$\begin{array}{c}\text { Complicated/ } \\
\text { Easy }\end{array}$} & - & - & - & - & $10 \%$ & $60 \%$ & $30 \%$ \\
\hline & & $30 \%$ & - & $40 \%$ & $20 \%$ & $10 \%$ & - & - \\
\hline & \multirow{2}{*}{$\begin{array}{c}\text { Confusing/ } \\
\text { Clear }\end{array}$} & - & - & - & - & - & $50 \%$ & $50 \%$ \\
\hline & & $10 \%$ & $30 \%$ & $30 \%$ & $10 \%$ & $10 \%$ & $10 \%$ & - \\
\hline \multirow{8}{*}{ 莺 } & \multirow{2}{*}{$\begin{array}{c}\text { Slow/ } \\
\text { Fast } \\
\end{array}$} & - & - & - & - & $10 \%$ & $60 \%$ & $30 \%$ \\
\hline & & $10 \%$ & $10 \%$ & $60 \%$ & $20 \%$ & - & - & - \\
\hline & \multirow{2}{*}{$\begin{array}{c}\text { Inefficient/ } \\
\text { Efficient }\end{array}$} & - & - & - & - & $20 \%$ & $40 \%$ & $40 \%$ \\
\hline & & - & $20 \%$ & $30 \%$ & $30 \%$ & $10 \%$ & $10 \%$ & - \\
\hline & \multirow{2}{*}{$\begin{array}{c}\text { Impractical/ } \\
\text { Practical }\end{array}$} & 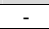 & - & - & - & $20 \%$ & $60 \%$ & $20 \%$ \\
\hline & & $10 \%$ & $40 \%$ & - & $40 \%$ & $10 \%$ & & \\
\hline & \multirow{2}{*}{$\begin{array}{c}\text { Cluttered/ } \\
\text { Organize }\end{array}$} & - & - & - & - & $20 \%$ & $40 \%$ & $40 \%$ \\
\hline & & $20 \%$ & $20 \%$ & $40 \%$ & $10 \%$ & $10 \%$ & - & - \\
\hline \multirow{8}{*}{ 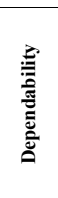 } & Unpredictable/ & - & - & - & $40 \%$ & - & $60 \%$ & - \\
\hline & Predictable & $10 \%$ & $20 \%$ & $30 \%$ & $40 \%$ & - & - & - \\
\hline & Obstructive/ & - & - & - & $10 \%$ & $10 \%$ & $50 \%$ & $30 \%$ \\
\hline & Supportive & $10 \%$ & $10 \%$ & $40 \%$ & $30 \%$ & - & $10 \%$ & - \\
\hline & Not secure/ & - & - & - & $20 \%$ & $20 \%$ & $50 \%$ & $10 \%$ \\
\hline & Secure & $10 \%$ & $10 \%$ & $40 \%$ & $30 \%$ & $10 \%$ & - & - \\
\hline & Not meet expectation/ & - & - & - & $10 \%$ & $20 \%$ & $50 \%$ & $20 \%$ \\
\hline & Meet expectation & $10 \%$ & $20 \%$ & $40 \%$ & - & $30 \%$ & - & - \\
\hline & Inferior/ & - & - & - & $10 \%$ & - & $60 \%$ & $30 \%$ \\
\hline & Valuable & - & $20 \%$ & $60 \%$ & $20 \%$ & - & - & - \\
\hline & Boring/ & 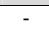 & - & - & - & - & $40 \%$ & $60 \%$ \\
\hline 急 & Exciting & $20 \%$ & - & $30 \%$ & $40 \%$ & $10 \%$ & - & - \\
\hline $\bar{E}$ & Not interesting/ & - & - & - & - & - & $50 \%$ & $50 \%$ \\
\hline 表 & Interesting & $10 \%$ & $30 \%$ & $30 \%$ & $20 \%$ & $10 \%$ & - & - \\
\hline & Demotivating/ & - & - & - & - & $30 \%$ & $50 \%$ & $20 \%$ \\
\hline & Motivating & $10 \%$ & $30 \%$ & $30 \%$ & $20 \%$ & $10 \%$ & - & - \\
\hline & Dull/ & 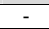 & - & 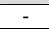 & - & - & $50 \%$ & $50 \%$ \\
\hline & Creative & $40 \%$ & $20 \%$ & $20 \%$ & $20 \%$ & - & - & - \\
\hline & Conventional/ & - & $10 \%$ & $10 \%$ & - & - & $60 \%$ & $20 \%$ \\
\hline ప & Inventive & $20 \%$ & $10 \%$ & $30 \%$ & $10 \%$ & $20 \%$ & $10 \%$ & - \\
\hline 0 & Usual/ & - & - & - & - & $50 \%$ & $50 \%$ & - \\
\hline & Leading-edge & $20 \%$ & $10 \%$ & $30 \%$ & $40 \%$ & . & - & 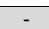 \\
\hline & Conservative/ & & - & 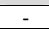 & - & - & $80 \%$ & $20 \%$ \\
\hline & Innovative & $10 \%$ & $30 \%$ & $20 \%$ & $20 \%$ & $10 \%$ & $10 \%$ & - \\
\hline
\end{tabular}

Based on the results, the scales mean values show very positive impressions for Agri-Snaps, ranging from 1.53 to 2.38 for all aspects of user experience. This indicates that the participant's judgment of Agri-Snaps was that it was attractive, easy to understand, efficient, reliable, stimulating, and innovative. In contrast, the scales mean values for the typical IoT agriculture system leaned towards negative impressions, with the scores ranging from -0.83 to -1.23 . This result validates that although the typical system provided useful agriculture monitoring data, the participants seemed demotivated to depend on and use it when compared to AgriSnaps. They felt the typical system was unattractive, difficult to understand, less efficient, unreliable, uninteresting and failed to grab their attention.

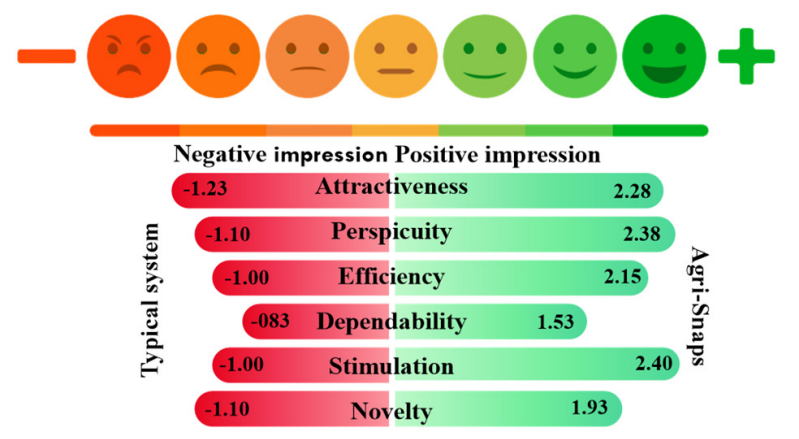

Fig. 13. Overall results for UEQ items, per scale.

For Agri-Snaps, Dependability was the least positively rated scale among the participants $(\mathrm{M}=1.53)$. The results suggested that participants may have difficulty predicting where the sensor modules should be snapped together with the controller module as $40 \%$ of participants rated Agri-Snaps as neither unpredictable nor predictable, $10 \%$ found it to be neither obstructive nor destructive and neither meet their expectation or not, and 20\% felt Agri-Snaps as neither insecure nor secure. It can be speculated that the icon embossed on top of the controller and sensor module enclosures was not clearly visible to the user. Therefore, instead of referring to the embossed icon, the design of Agri-Snaps can be improved by changing the color of the controller module slot joint. Instead of using a white color scheme, the controller module slot joint should be matched with the color of the sensor modules. For example, the blue color slot joint at the controller module is to be attached with the blue color sensor module. This design approach will allow the user to instantaneously rely on the color scheme when assembling the Agri-Snaps. Nonetheless, $50 \%$ of the participants rated Agri-Snaps as supportive, secure, and meeting their expectations, whereas $60 \%$ of the participants found the design of Agri-Snaps as predictable.

In contrast, Stimulation was the most positively evaluated scale $(M=2.40)$, in which $60 \%(+2)$ of the participants found it to be exciting and $50 \%(+2)$ of them rated Agri-Snaps as motivating. Also, half of the participants found the design of Agri-Snaps was positively interesting (+3). The results proved that Agri-Snaps has improved the way the participants perceived the IoT system as more valuable than the typical system. Although both systems were able to produce the same IoT data visualization, the enhanced design of Agri-Snaps made the participants feel more motivated and interested in implementing the IoT system in their farm field.

Perspicuity was the second most positively evaluated scale $(\mathrm{M}=2.38) .60 \%$ of the participants found Agri-Snaps as understandable and easy $(+2)$. Whereas $50 \%$ of the participants rated Agri-Snaps as easy to learn and clear $(+3)$. This indicated that when compared to the typical system, the intuitive design 
of Agri-Snaps managed to develop a better understanding of how to assemble, self-troubleshoot, and maintain the system independently without much effort. It should be noted that allowing the farmers to have a thorough understanding and a firm knowledge of the system is critical in order to galvanize and sustain their interest in the use of IoT.

Attractiveness and Efficiency were the third and fourth positively evaluated scales with $\mathrm{M}=2.28$ and $\mathrm{M}=2.15$ respectively. These results indicated that the participants liked Agri-Snaps and could practically assemble the system without unnecessary effort. This was reflected when $60 \%$ of participants rated Agri-Snaps as fast to assemble and practical $(+3)$. Also, $80 \%$ of the participants rated Agri-Snaps's design as efficient and organized $(+2$ to +3$)$. Moreover, $90 \%$ of the participants found Agri-Snaps as pleasing $(+3)$, whereas $60 \%$ rated the design of Agri-Snaps as friendly and good $(+3)$.

Novelty was the participants' second least positively rated scale $(M=1.93)$, in which $20 \%$ of the participants found AgriSnaps's design as conventional $(-1$ to -2$)$. The results suggested that despite Agri-Snaps's inventive design, only 4 sensors were integrated into the system, limiting its capability to detect other changes in environmental conditions. However, it is a good starting point to investigate whether the design of Agri-Snaps can improve the farmers' acceptance of using IoT technology in their farm field. Nonetheless, based on Figure 13 and Table I, the design of Agri-Snaps has been positively accepted among the participants compared to the typical IoT agriculture monitoring system.

\section{FUTURE WORK AND CONCLUSION}

Future work should further improve the design of AgriSnaps by integrating more sensor modules, as illustrated in Figure 15 . The variety of sensors allows the farmer to choose which sensor modules are required to cater the crop grown on their farm field. In conclusion, the design of Agri-Snaps successfully allows the user to easily understand how to assemble, self-troubleshoot, and maintain the system independently without requiring an extensive understanding of IoT technology and electronic concepts. These features enable the farmers to improve their acceptance towards implementing IoT technology in their farm fields.

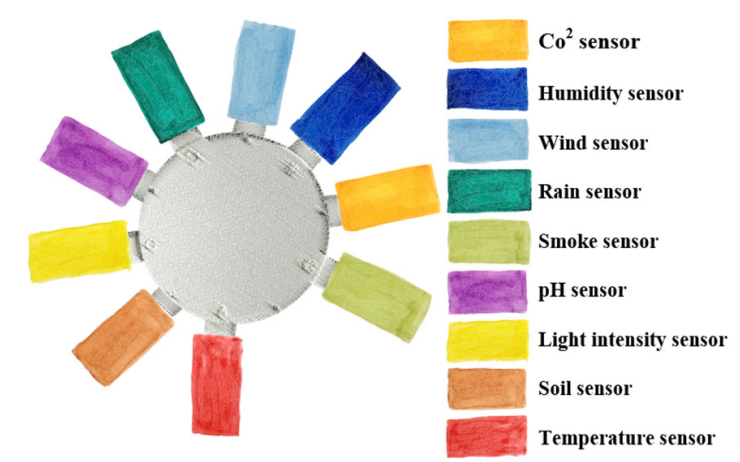

Fig. 14. The design concept of Agri-Snaps with more sensor modules integration.

\section{ACKNOWLEDGEMENT}

The authors wish to acknowledge the support from the Ministry of Higher Education of Malaysia (MOHE), Advanced Sensors and Embedded Control (ASECs) Research Group, Centre for Telecommunication Research \& Innovation (CeTRI), Fakulti Kejuruteraan Elektronik dan Kejuruteraan Komputer (FKEKK), Universiti Teknikal Malaysia Melaka (UTeM), Hang Tuah Jaya, Durian Tunggal, Melaka, Malaysia. This work was financially supported by UTeM Internal Grant (PJP/2020/FKEKK/PP/S01759)

\section{REFERENCES}

[1] V. Narayanamurthy and F. Samsuri, "Perspectives of a Farmer Digital Expert Assistant System," Engineering, Technology \& Applied Science Research, vol. 6, no. 2, pp. 972-975, Apr. 2016, https://doi.org/10. 48084/etasr.642.

[2] K. G. Arvanitis and E. G. Symeonaki, "Agriculture 4.0: The Role of Innovative Smart Technologies Towards Sustainable Farm Management," The Open Agriculture Journal, vol. 14, no. 1, Aug. 2020, https://doi.org/10.2174/1874331502014010130.

[3] D. Glaroudis, A. Iossifides, and P. Chatzimisios, "Survey, comparison and research challenges of IoT application protocols for smart farming," Computer Networks, vol. 168, Feb. 2020, Art. no. 107037, https://doi.org/10.1016/j.comnet.2019.107037.

[4] N. C. Eli-Chukwu, "Applications of Artificial Intelligence in Agriculture: A Review," Engineering, Technology \& Applied Science Research, vol. 9, no. 4, pp. 4377-4383, Aug. 2019, https://doi.org/ 10.48084/etasr.2756.

[5] I. Mat, M. R. Mohd Kassim, A. N. Harun, and I. M. Yusoff, "Smart Agriculture Using Internet of Things," in 2018 IEEE Conference on Open Systems (ICOS), Langkawi, Malaysia, Nov. 2018, pp. 54-59, https://doi.org/10.1109/ICOS.2018.8632817.

[6] M. S. A. Mahmud, S. Buyamin, M. M. Mokji, and M. S. Z. Abidin, "Internet of Things based Smart Environmental Monitoring for Mushroom Cultivation," Indonesian Journal of Electrical Engineering and Computer Science, vol. 10, no. 3, pp. 847-852, Jun. 2018, https://doi.org/10.11591/ijeecs.v10.i3.pp847-852.

[7] M. R. M. Kassim, I. Mat, and I. M. Yusoff, "Applications of Internet of Things in Mushroom Farm Management," in 2019 13th International Conference on Sensing Technology (ICST), Sydney, Australia, Dec. 2019, pp. 1-6, https://doi.org/10.1109/ICST46873.2019.9047702.

[8] S. A. H. Z. Abidin and S. N. Ibrahim, "Web-based monitoring of an automated fertigation system: An IoT application," in 2015 IEEE 12th Malaysia International Conference on Communications (MICC), Kuching, Malaysia, Nov. 2015, pp. 1-5, https://doi.org/10.1109/ MICC.2015.7725397.

[9] F. A. Khan, A. Abubakar, M. Mahmoud, M. A. Al-Khasawneh, and A. A. Alarood, "Cotton Crop Cultivation Oriented Semantic Framework Based on IoT Smart Farming Application," International Journal of Engineering and Advanced Technology, vol. 8, no. 3, pp. 480-484, Feb. 2019.

[10] I. Mat, M. R. Mohd Kassim, A. N. Harun, and I. Mat Yusoff, "IoT in Precision Agriculture applications using Wireless Moisture Sensor Network," in 2016 IEEE Conference on Open Systems (ICOS), Langkawi, Malaysia, Oct. 2016, pp. 24-29, https://doi.org/10.1109/ ICOS.2016.7881983.

[11] M. I. H. bin Ismail and N. M. Thamrin, "IoT implementation for indoor vertical farming watering system," in 2017 International Conference on Electrical, Electronics and System Engineering (ICEESE), Kanazawa, Japan, Nov. 2017, pp. 89-94, https://doi.org/10.1109/ICEESE.2017. 8298388.

[12] M. F. Mohamad Jaafar, H. Hussin, R. Rosman, T. Y. Kheng, and M. Ja' afar Hussin, "Smart Cocoa Nursery Monitoring System Using IRT for Automatic Drip Irrigation," in 2019 IEEE 13th International Conference on Telecommunication Systems, Services, and Applications (TSSA), Bali, 
Indonesia, Oct. 2019, pp. 108-113, https://doi.org/10.1109/TSSA48701. 2019.8985463 .

[13] S. Zafar, G. Miraj, R. Baloch, D. Murtaza, and K. Arshad, "An IoT Based Real-Time Environmental Monitoring System Using Arduino and Cloud Service," Engineering, Technology \& Applied Science Research, vol. 8, no. 4, pp. 3238-3242, Aug. 2018, https://doi.org/10.48084/ etasr.2144.

[14] L. Kuo, T. Chang, and C.-C. Lai, "Research on product design modeling image and color psychological test," Displays, vol. 71, Jan. 2022, Art. no. 102108, https://doi.org/10.1016/j.displa.2021.102108.

[15] S. J. P. McDougall, O. de Bruijn, and M. B. Curry, "Exploring the effects of icon characteristics on user performance: The role of icon concreteness, complexity, and distinctiveness," Journal of Experimental Psychology: Applied, vol. 6, no. 4, pp. 291-306, 2000, https://doi.org/ 10.1037/1076-898X.6.4.291.

[16] O. Visser, S. R. Sippel, and L. Thiemann, "Imprecision farming? Examining the (in)accuracy and risks of digital agriculture," Journal of Rural Studies, vol. 86, pp. 623-632, Aug. 2021, https://doi.org/ 10.1016/j.jrurstud.2021.07.024.

[17] A. Bdeir, "Electronics as material: littleBits," in Proceedings of the 3rd International Conference on Tangible and Embedded Interaction, New York, NY, USA, Feb. 2009, pp. 397-400, https://doi.org/10.1145/ 1517664.1517743 .

[18] A. B. Hollingshead, "The Rank-Order Effect in Group Decision Making," Organizational Behavior and Human Decision Processes, vol. 68, no. 3, pp. 181-193, Dec. 1996, https://doi.org/10.1006/obhd. 1996.0098.

[19] M. Schrepp, J. Thomaschewski, and A. Hinderks, "Construction of a Benchmark for the User Experience Questionnaire (UEQ)," International Journal of Interactive Multimedia and Artificial Intelligence, vol. 4, no. 4, pp. 40-44, Jun. 2017, https://doi.org/ 10.9781/ijimai.2017.445. 